\section{Polar rescue: science was not well served}

Following the rescue of passengers from the stranded Russian ship MV Akademik Shokalskiy, the expedition's leader, Chris Turney, has spoken out about the importance of science as a driver for the voyage (Nature 505, 133; 2014). No nation hesitates to aid vessels in distress, so why have these events proved so controversial?

Turney said that the "science case" for the voyage was approved by, among others, the Australian Antarctic Division (AAD). But the AAD had no role in assessing, endorsing or approving the scientific merit of the expedition's research plans.

Turney's expedition was a private venture whose research plans were unrelated to Australia's national Antarctic science programme, which is led and managed by the AAD. His voyage aimed to "meld science and adventure" and included as many paying tourists as it did scientists and students (www. spiritofmawson.com).

The rescue disrupted the science and operations programmes of Australia, China and France, who all diverted their ships at the request of the Australian Rescue Coordination Centre, which ran the aid operation. A US icebreaker was also diverted. The financial cost of the exercise is not yet known.

Critics have questioned Turney's claims regarding the scientific importance of the voyage. The trip was relatively brief and seemed to involve the collection of routine samples. By contrast, research projects supported by national polar programmes are multi-year, multinational efforts that rely on sophisticated bespoke equipment.

As a result, Turney's expedition has sparked yet another poorly informed debate on climate science and has seen issues associated with independent Antarctic tourism get conflated with the conduct of Antarctic science. Science is invariably the loser in such cases.

Nick Gales Australian Antarctic Division, Kingston, Tasmania, Australia. nick.gales@aad.gov.au

\section{Shift aims of China's poorer universities}

China's universities and research institutes are experiencing the 'Matthew effect', whereby powerful institutions become stronger and weaker ones become even weaker. It is in the country's long-term interest to rectify this by shifting the educational focus of less-prestigious universities to help domestic job seekers.

Chinese academic institutions are clamping down on the recruitment of research staff as the market becomes saturated with domestic $\mathrm{PhD}$ graduates. The toptier universities (known as '985 Project' institutions; see H. Zhang et al. Res. Policy 42, 765-775; 2013) set the most stringent entry requirements, demanding high qualifications from leading and overseas institutions.

The aim seems to be to attract international talent, as outlined in the government's Recruitment Program of Global Experts, with a view to creating several worldclass academic universities in China. To this end, the leading universities have already received a large amount of financial and other support. At the same time, 'ordinary' universities are becoming less competitive as they lose the power to draw in resources and the best people.

To restore the balance, we suggest that these less powerful universities should focus on offering vocational education programmes (see Q. Wang Nature 499, 381; 2013) or training students for high-level positions outside academia (see Nature 472, 276-279; 2011). Yanhong Tang, Xin Miao Harbin Institute of Technology, Harbin, China. xin.miao@aliyun.com

\section{Rapid progress in producing graphene}

Your discussion on developments in graphene research might give the erroneous impression that we are decades away from a commercially viable method of graphene production on an industrial scale (see Nature 503, 327-329; 2013).

In fact, over the past few years the ability to grow large tracts of graphene and transfer it to multiple substrates, as well as doping, patterning and other techniques, have been developed to a point at which industrial production is progressing rapidly. You mention that the company Graphenea produces 15 square metres of graphene per year. But other companies have superior production capabilities: US-based Bluestone Global Tech, for example, has the capacity to produce 20-200 square metres of graphene per day (see go.nature. com/gja2bo).

The production cost you quote of up to US $\$ 100,000$ per square metre is actually a retail price for just a few square centimetres of material. The cost of producing it is in fact much lower. Production costs have fallen rapidly in the past few months at Bluestone Global Tech, thanks to an increase in production volumes and new transfer techniques. Kostya S. Novoselov ${ }^{\star}$ University of Manchester, UK.

kostya@manchester.ac.uk ${ }^{*}$ On behalf of 4 co-signatories (see go.nature.com/utk5pk for full list).

\section{Use multimedia in grant applications}

The format of grant applications should be updated to incorporate multimedia video. This would help researchers to convey complex topics to grant-review panels.

If time-poor research panels cannot quickly grasp the scientific ideas presented in a paper application, other factors, such as author affiliations and track records, may disproportionately influence project rankings.

We contend that dense proposals presented in a more accessible multimedia format will enhance reviewer comprehension, and so preserve the effectiveness of the meritbased grant-ranking system and boost the research benefit from increasingly scarce public funds.

Researchers already routinely use videos to communicate complex scientific concepts and methods at conferences and in online journals and seminars. Ironically, the US National Institutes of Health even uses YouTube video presentations to instruct applicants on how to prepare paper grant applications. Michael R. Doran, William B. Lott Queensland University of Technology, Brisbane, Australia. michael.doran@qut.edu.au Steven E. Doran University of Illinois, Urbana-Champaign, USA.

\section{Publish on the basis of quality, not gender}

The publication of research papers should be based on quality and merit, so the gender balance of authors is not relevant in the same way as it might be for commissioned writers (see Nature $\mathbf{5 0 4}, \mathbf{1 8 8}$; 2013). Neither is the disproportionate number of male reviewers evidence of gender bias.

Having young children may prevent a scientist from spending as much time publishing, applying for grants and advancing their career as some of their colleagues. Because it is usually women who stay at home with their children, journals end up with more male authors on research articles. The effect is exacerbated in fast-moving fields, in which taking even a year out threatens to leave a researcher far behind.

This means that there are likely to be more men in the pool of potential referees.

Lukas Koube Sherman, Texas, USA.

lukas.koube@gmail.com 


\section{EDITOR'S NOTE}

Nature has a strong history of supporting women in science and of reflecting the views of the community in our pages, including Correspondence.

Our Correspondence pages do not reflect the views of the journal or its editors; they reflect the views only of the correspondents.

We do not endorse the views expressed in the Correspondence 'Publish on the basis of quality, not gender' (Nature 505, 291; 2014) - or indeed any Correspondences unless we explicitly say so. On re-examining this letter and the process, we consider that it adds no value to the discussion and unnecessarily inflames it, that it did not receive adequate editorial attention, and that we should not have published it, for which we apologize.

Nature's own positive views and engagement in the issues concerning women in science are represented by our special from 2013: www.nature.com/ women.

Philip Campbell, Editor-in-Chief, Nature 